\title{
Trademark Value Evaluation Based on Language Operator - Fuzzy Real Option Simulation Pricing Model
}

\author{
Peimin Ren ${ }^{1, *}$, Shuran Zhao ${ }^{2}$ and Miao Zhang ${ }^{3}$ \\ ${ }^{1}$ School of Economics, Qingdao University, Qingdao, China \\ ${ }^{2}$ School of Economics, Ocean University of China, Qingdao, China \\ ${ }^{*}$ Corresponding author
}

\begin{abstract}
This study applies language operators, trapezoidal fuzzy number, and real option to construct the trademark value evaluation model. Because of the uncertainty of future revenue and investment of the trademark utilization, compared with the traditional method, the Parameter estimation will complies with the reality better by using language operator. Meanwhile, uncertainty also means trademark process contains a number of options in the future. Therefore, this paper construct the fuzzy real option brand value evaluation model which Consistent with the actual situation more, and contain the Opportunity value. And an example is used to illustrate this method.
\end{abstract}

Keywords-trademark valuation; fuzzy real option; language operator

\section{INTRODUCTION}

Trademark is not only the identify of goods or Service producer, or the identify by which the vast number of consumers distinguish the goods or services, but condensing the embodiment of comprehensive quality of enterprise's goods or services, represents the company's image. According to United States Wall Street data, the return level and earnings level of the enterprise which have a famous trademark generally are higher than the similar enterprises which have common trademark. Trading activities of trademarks such as merger, acquisition, transfer, investment, mortgage, corporate joint ventures, bankruptcy audit transactions in today's society is more and more frequent, In many of the deals, people need to determine the value of trademarks, trademark valuation become the focus of increasing concern. Selecting appropriate and suitable evaluation methods have become the very important issues in trademarks evaluation field.As to the method, with the depth of research and practice, and because of the different Observation angle of the researchers, there are numerous methods of trademark evaluation in the world. Reasoned principle behind the method, Methods can be broadly divided into the following categories:

The first category is income method. This method discount the benefits increased by the trademark to get the trademark value. Clifford (1995) describes in detail how to determine income discount rate. The second category is the market value method. Compared with the valuation of similar trademark in the market, the object value is obtained. Third category is the cost method. It evaluates trademarks by the trademark cost.
Kuhle and Moorehead (1990) amendments theoretically the cost method, they used statistical methods to complement the deficiency in the cost method. Category IV is the mixed evaluation method. It combined the trademark characteristics and the first three methods, to comprehensive evaluate the trademarks. Now the assessment method of famous trademark at the international level is Interbrand method proposed by United Kingdom Interbrand Group Company. Interbrand method scores the various parameters which affect the value of trademarks, then trademark intensities is calculated by giving weight to score values, then value multiples is calculated by the trademarks intensities.

Traditional trademarks evaluation methods such as cost, market, income method are mainly based on some regular factors and conditions of the tangible assets. Because of the analogical example is not easy to find, lack of Market infrastructure to forecast income, discounted rates and income term poorly defined features, these methods have limitations.

In fact, if there are continuously substantial revenue by using the trademark, companies will continue to invest, enhance the products quality, services, after-sale and so on various aspects. If the trademark is unable to bring extra benefits to the companies, companies can stop the injection. Enterprise has the right to make choices, choices such as continue, abandon or delay to Inject funds to the trademark and other decisions.

Based on the above analysis, real option is introduced to the trademark research. Real option method analyzes various parameter settings of the income stream in combination with trademark characteristics. Based on the Income method, it regarded the rights to hold or develop trademark and the ability to avoid or control risks as option. It calculates the trademark option values by using analytical, numerical calculation method.

Reiss (1998) earlier stated that intellectual property rights can be evaluated by real option. Taylor (2009) pointed out that during the process of trademarks financing, there contains the renew options, Redemption options; sell options, etc. But the quantitative analysis is lack.Tang (2008) noted that the trademark value can be reasonable priced by overlapping a series of jump option. Dai (2010) attempts to apply the 
binomial option pricing model in the trademark value assessment.

In these studies, there are problems such as without quantitatively analysis, or not taking into account various options compound. Meanwhile, there are also parameters problems such as the future benefits of trademark; investment costs cannot be accurately predicted.

Based on the above analysis, due to the future parameter prediction of trademark has the fuzzy and subjective characteristics, this paper use language operators such as very good, good, to measure trademarks parameters such as present value of future earnings and investment. Each language operators corresponds to a trapezoidal fuzzy number, and assigned a occurrence probability. On this basis, considering the trademark value contains a variety of options, we use modified fuzzy real option pricing formula to study trademark evaluation. then empirical analysis is operated. The research is more in line with the trademark assessment data, has a certain significance.

The study is organized as follows; the second part describes the trapezoidal fuzzy number and fuzzy real option theory. Section III describes the data and discusses empirical findings. Part IV reviews, we came to the conclusion.

\section{THE THEORY OF TRAPEZOID FUZZY NUMBER}

\section{A. Trapezoid Fuzzy Numbers}

In the course of describing the Model in detail, trapezoidal fuzzy number is used to represent expert language evaluation. Compared with triangular fuzzy numbers, in terms of accuracy and suitability of language value conversion, trapezoidal fuzzy number will be closer to the actual value, so the results are more accurate. Therefore, trapezoidal fuzzy number is used to solve the problem.

\section{B. Definition of Trapezoid Fuzzy Number}

Fuzzy sets $\tilde{A} \in F$ were called as the trapezoidal fuzzy number whose the left widths is $\alpha$ and right width is $\beta$ on the real line ${ }^{[a, b]}$, if its membership function satisfies

$$
\tilde{A}(t)=\left\{\begin{array}{c}
1-\frac{a-t}{\alpha}, \text { when } a-\alpha \leq t<a \\
1 \text {, when } a \leq t<b \\
1-\frac{t-b}{\beta}, \text { when } b \leq t \leq b+\beta \\
0, \text { another }
\end{array}\right.
$$

Can be expressed as $\tilde{A}=(a, b, \alpha, \beta)$, as shown in Figure 1 .

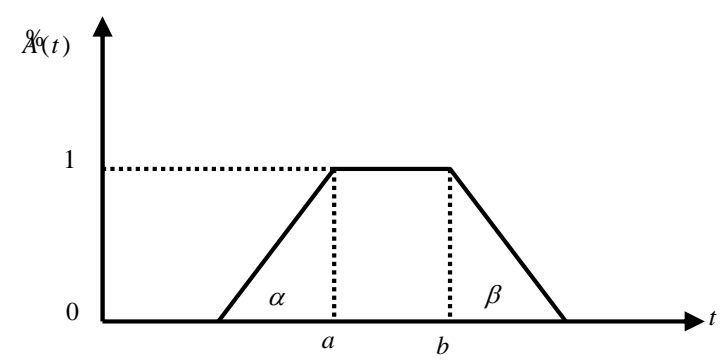

FIGURE I. TRAPEZOID FUZZY NUMBER

C. The Expectation and Variance of Trapezoidal Fuzzy Number

Define trapezoidal fuzzy number $\gamma_{\text {cut sets }}$

$[\mathscr{A}]_{\gamma}=[a-(1-\gamma) \alpha, b+(1-\gamma) \beta], \forall \gamma \in[0,1] \cdot \gamma$ is confidence level. Its collection is $(a-\alpha, b+\beta)$, if $\gamma$ - cut sets $[\tilde{A}]_{\gamma}=\left[a_{1}(\gamma), a_{2}(\gamma)\right],[\tilde{B}]_{\gamma}=\left[b_{1}(\gamma), b_{2}(\gamma)\right]$ is fuzzy sets, $\lambda$ is a real number, by the extension principle, we can get

$$
[\tilde{A}+\tilde{B}]_{\gamma}=\left[a_{1}(\gamma)+b_{1}(\gamma), a_{2}(\gamma)+b_{2}(\gamma)\right],[\lambda \tilde{A}]_{\gamma}=\lambda[\tilde{A}]_{\gamma}
$$

Introduce the concept of fuzzy number mean

$$
E(\tilde{A})=\int_{0}^{1} \gamma\left[a_{1}(\gamma)+a_{2}(\gamma)\right] d \gamma=\frac{\int_{0}^{1} \gamma \frac{a_{1}(\gamma)+a_{2}(\gamma)}{2} d \gamma}{\int_{0}^{1} \gamma d \gamma}
$$

If $\tilde{A}=(a, b, \alpha, \beta)$ is a trapezoid fuzzy number, then

$$
E(\tilde{A})=\frac{a+b}{2}+\frac{\beta-\alpha}{6}
$$

$$
D(\tilde{A})=\frac{(b-a)^{2}}{4}+\frac{(b-a)(\alpha+\beta)}{6}+\frac{(\alpha+\beta)^{2}}{24}
$$

\section{TRademark Value Evaluation Model Based on LANGUAGE OPERATOR- FUZZY REAL OPTION}

\section{A. Trade Mark Corresponds to the Language of the Project Operator-Fuzzy Evaluation.}

Assume experts evaluate the corresponding parameters of the trademark by using the fuzzy comprehensive method,

For the Present value of cash flow obtained by trademark injection, the corresponding fuzzy number set of language operator (very high, high, medium, low, very low) ${ }_{\text {is }} P=\left(\tilde{P}_{1}, \tilde{P}_{2}, \tilde{P}_{3}, \tilde{P}_{4}, \tilde{P}_{5}\right)$, the occurred probability respectively is $W=\left(w_{1}, w_{2}, w_{3}, w_{4}, w_{5}\right), \tilde{P}$ represents present value of cash flow 
after trademark get injection, is the underlying assets value of current option; set $\tilde{P}$ as trapezoidal fuzzy number $\tilde{P}=\left(P_{1}, P_{2}, \alpha_{1}, \alpha_{2}\right)$, according to trapezoidal fuzzy number operation law, can get,

$$
\tilde{P}=\left(P_{1}, P_{2}, \alpha_{1}, \alpha_{2}\right)=P W^{\prime}
$$

The present value of cost obtained by trademark injection, the corresponding fuzzy number set of language operator (very high, high, medium, low, very low) is $C=\left(\tilde{C}_{1}, \tilde{C}_{2}, \tilde{C}_{3}, \tilde{C}_{4}, \tilde{C}_{5}\right)$, the occurred probability respectively is $V=\left(v_{1}, v_{2}, v_{3}, v_{4}, v_{5}\right)$,

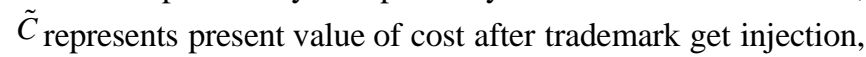
is the exercise price of current option; set $\tilde{C}$ as trapezoidal fuzzy number $\tilde{C}=\left(C_{1}, C_{2}, \beta_{1}, \beta_{2}\right)$, according to trapezoidal fuzzy number operation law, can get,

$$
\tilde{C}=\left(C_{1}, C_{2}, \beta_{1}, \beta_{2}\right)=C V^{\prime}
$$

\section{B. The Fuzzy Option Pricing Formula}

1) Fuzzy B-S option pricing formula

$$
\begin{gathered}
\tilde{V}=\tilde{P} e^{-\delta T} N\left(d_{1}\right)-\tilde{C} e^{-r T} N\left(d_{2}\right) \\
\tilde{V}=\left(V_{1}, V_{2}, \theta_{1}, \theta_{2}\right) \\
V_{1}=P_{1} e^{-\delta T} N\left(d_{1}\right)-C_{2} e^{-r T} N\left(d_{2}\right), \\
V_{2}=P_{2} e^{-\delta T} N\left(d_{1}\right)-C_{1} e^{-r T} N\left(d_{2}\right) \\
\theta_{1}=\alpha_{1} e^{-\delta T} N\left(d_{1}\right)+\beta_{2} e^{-r T} N\left(d_{2}\right), \\
\theta_{2}=\alpha_{2} e^{-\delta T} N\left(d_{1}\right)+\beta_{1} e^{-r T} N\left(d_{2}\right)
\end{gathered}
$$

2) Fuzzy binomial tree pricing formula: Based on the Parameter calculation method of binary tree model, parameters of binary trees is as follows:

$$
u=e^{\sigma \sqrt{\Delta t}}, d=e^{-\sigma \sqrt{\Delta t}}, f=e^{r \Delta t}, p=\frac{f-d}{u-d}
$$

Among them, $u$ is the increase multiplier, $d$ is the decrease multiplier, $p$ is the rising probability, $\sigma$ is the volatility for trapezoidal fuzzy number.
In the above formula, project value, investment value, options are trapezoid fuzzy number. Trapezoidal fuzzy number operations as previously described.

\section{The Rate of Contribution of Trademark}

During the operation of projects, the value of project is influenced not only by the trademarks, but also by the management, marketing, technology, and other factors. Therefore, the contribution of Trademark to project interest should be considered. The rate of contribution of trademark is between $(0-30 \%)$, most companies take the median $\mathrm{I}=15 \%$.

\section{The Trademark Value Calculation}

Trademark value is

$$
V^{\prime}=\tilde{V} I
$$

$V^{\prime}$ denotes trapezoidal fuzzy number. And we can further calculate the expectation and variance of $V^{\prime}$.

\section{NUMERICAL EXAMPLES}

A cell phone company was formally established in April 2010 , is a new technology company. We get the following data by the public information.

\section{A. Determinations of Parameter Values}

1) The risk-free rate $r$ : The risk-free rate $r$ is a very important parameter. In General, there are risks in any market, risk-free interest rate is the assumption of an ideal State, does not exist in practice.In view of this, Market risk-free interest rates generally are replaced with less risky investment interest rates, such as residents ' savings interest rate, Treasury bills interest rate or period Treasury rates are adopted as the approximate value of the risk-free rate. This article takes the averages (5.32\%) of 10-year China's Treasury bond interest rates as the value of the risk-free rate.

2) The duration $t$ of option: 5 years are adopted which is recommended by Interbrand Group Company.

3) The calculation of underlying asset value and cost: For the Present value of cash flow obtained by trademark injection, the corresponding fuzzy number set of language operator (very high, high, medium, low, very low) is $P=\left(\tilde{P}_{1}, \tilde{P}_{2}, \tilde{P}_{3}, \tilde{P}_{4}, \tilde{P}_{5}\right)$, the occurred probability respectively is $W=\left(w_{1}, w_{2}, w_{3}, w_{4}, w_{5}\right)=(0.2,0.1,0.3,0.2,0.2)$,

The present value of cost obtained by trademark injection, the corresponding fuzzy number set of language operator (very high, high, medium, low, very low $)$ is $C=\left(\tilde{C}_{1}, \tilde{C}_{2}, \tilde{C}_{3}, \tilde{C}_{4}, \tilde{C}_{5}\right)$, the occurred probability respectively is $V=\left(v_{1}, v_{2}, v_{3}, v_{4}, v_{5}\right)=(0.2,0.1,0.3,0.2,0.2)$, Values of $\mathrm{P}$ and $\mathrm{C}$ are as shown in table 1 below 
TABLE I. THE TRAPEZOIDAL FUZZY NUMBER OF INCOME AND COST

\begin{tabular}{|l|l|l|}
\hline \multirow{2}{*}{$\begin{array}{c}\text { Lang } \\
\text { uage } \\
\text { oper } \\
\text { ators }\end{array}$} & \multicolumn{2}{|c|}{ Trapezoidal Fuzzy Number } \\
\cline { 2 - 3 } & Income trapezoidal fuzzy number & $\begin{array}{c}\text { Cost trapezoidal fuzzy } \\
\text { number }\end{array}$ \\
\hline $\begin{array}{l}\text { very } \\
\text { high }\end{array}$ & $(100122,100422,101022,101322)$ & $(90992,91292,91892,92192)$ \\
\hline high & $(57453,57753,58353,58653)$ & $(52159,52459,53059,53359)$ \\
\hline $\begin{array}{l}\text { medi } \\
\text { um }\end{array}$ & $(30852,31152,31752,32052)$ & $(27971,28271,28871,29171)$ \\
\hline low & $(15174,15474,16074,16374)$ & $(13703,14003,14603,14903)$ \\
\hline $\begin{array}{l}\text { very } \\
\text { low }\end{array}$ & $(6555,6855,7455,7755)$ & $(5856,6156,6756,7056)$ \\
\hline
\end{tabular}

By using the fuzzy calculation formulas, the comprehensive trapezoidal fuzzy number of benefits $\tilde{P}$ is (39371, 39671, 40271, 40571), $\tilde{P}$ represents present value of cash flow after trademark get injection, is the underlying assets value of current option.

The comprehensive trapezoidal fuzzy number $\tilde{C}$ of cost is (35717,36017,36617,36917), $\tilde{C}_{\text {represents present value of cost }}$ after trademark get injection, is the exercise price of current option

The comprehensive trapezoidal fuzzy number are turned into the original expression $\widetilde{\mathrm{P}}=(39671,40271,300,300)$, $\tilde{C}=(36017,36617,300,300)$.

4) Option kolatility: By fuzzy number formula, $E(P)=39971, D(P)=165000$

In the General condition, if market transaction information is enough, option volatility can be calculated approximate by using the market price volatility of industrial stocks or industrial index. Due to insufficient model information, the volatility can only be represented approximately by the variable coefficient. According to the formula of variable coefficient, volatility can be calculated from the equation

$$
\sigma=\sqrt{D(\tilde{P})} / E(\tilde{P})=0.01
$$

\section{B. Trademark Value Based on Fuzzy B-S Option Pricing Formula}

Through the above, this case does not take into account more stages various type of compound real option, so fuzzy B$\mathrm{S}$ option pricing method can be used to evaluate the value of trademarks. Calculation results are as follows:

$$
\begin{gathered}
d_{1}=-0.70 \quad d_{2}=-0.92 N\left(d_{1}\right)=0.24, N\left(d_{2}\right)=0.18, \\
V_{1}=81.61, V_{2}=189.87, \theta_{1}=539.4, \theta_{2}=539.4 .
\end{gathered}
$$

Therefore, the fuzzy
is $\quad \tilde{V}=(81.61,189.87,539.4,539.4)$
is $E(\tilde{V})=135.74$

By the formula $V^{\prime}=\tilde{V I}$,

$$
V^{\prime}=(12.24,28.48,80.9,80.9)
$$

The most likely value range is $(12.24,28.48)$, Expected value is 2.0361 billion Yuan.

The Case shows that the most possible value range of the trademark value of a cell phone is $(12.24,28.48)$ billion.

In General, in most cases B-S model and two-binomial tree model is consistent with the assessed value, but in the case of multiple options, binomial tree model is more applicable than that of the Black-Scholes model. This example contains only simple call options, in view of this; the B-S model is used. The uncertain value of trademark is huge, which also coincided with the character of trademark value such as high profitability etc.

\section{CONCLUSIONS}

In real life, because the information is incomplete and difficult to access, policy makers are difficult to give a precise value in the actual evaluation process, so tend to use language to express their preference information. While in the process of research, qualitative data are generally required to be translated into quantitative data, which requires quantitative data can accurately replace the expert fuzzy language.

Trapezoidal fuzzy number is selected to represent the expert preference information in this paper. According to the analysis on the fuzzy compound real options characteristics of value, language operators corresponds to the present value of income and costs are translated into trapezoidal fuzzy number. And weights are given. Then the variance and expectations of trapezoidal fuzzy number are redefined, fuzzy compound real option pricing model was constructed for trademark evaluation.

Through analysis on the trademark value of some cell phone company, the company's trademark fuzzy real option value is obtained. The method combines fuzzy arithmetic, real options, and language operators which is more in line with trademark operation characteristics of uncertainty and selectivity.

\section{ACKNOWLEDGMENT}

This paper is funded by the Ministry of Education humanities and social sciences research project (No.: 12yjc630161), Qingdao University graduate key curriculum construction project (No.: QDYKC14010).

\section{REFERENCES}

[1] Kuhle, James L., and J. D. Moorehead. "Applying the Bootstrap Technique to Real Estate Appraisal: An Empirical Analysis." Journal of Real Estate Research 5.1 1990, pp.33-40. 
[2] Jr, Clifford E. Fisher. "Rates And Ratios Used In The Income Capitalization Approach." 1995.

[3] Donthu, Naveen. "Brand Equity, Brand Preference, and Purchase Intent."Journal of Advertising 24.3 1995, pp.25-40.

[4] Hardesty, David M., and W. O. Bearden. "Consumer evaluations of different promotion types and price presentations: the moderating role of promotional benefit level." Journal of Retailing 79.1 2003, pp.17-25..

[5] Reiss, Ariane. "Investment in innovations and competition: an option pricing approach." Quarterly Review of Economics \& Finance38.3 1998, pp.635-650.

[6] Taylor, Ruth L, et al. "Securitization of brand names: Basic concepts and its use in practice." Journal of Brand Management 17.1 2009, pp.62-83.

[7] Tang, C., Lu, H.” On the option pricing model of trademark right.” Journal of Chongqing Institute of Technology (Social Science), 22, 2008, pp. 29-31.

[8] Dai, Y." Research on methods of brand asset evaluation based on binominal option pricing." Science Technology and Engineering, 10, 2010, pp. 6591-6594.

[9] Panayi, Sylvia, and L. Trigeorgis. "Multi-stage real options: The cases of information technology infrastructure and international bank expansion."Quarterly Review of Economics \& Finance 38.3 1998, pp.675-692. 